\title{
Antagonistic signals within the COX2 mRNA coding sequence control its translation in Saccharomyces cerevisiae mitochondria
}

\author{
ELIZABETH H. WILLIAMS and THOMAS D. FOX \\ Department of Molecular Biology and Genetics, Cornell University, Ithaca, New York 14853-2703, USA
}

\begin{abstract}
Translation of the mitochondrially coded COX2 mRNA within the organelle in yeast produces the precursor of Cox $2 \mathrm{p}$ (preCox2p), which is processed and assembled into cytochrome $c$ oxidase. The mRNA sequence of the first 14 COX2 codons, specifying the pre-Cox $2 p$ leader peptide, was previously shown to contain a positively acting element required for translation of a mitochondrial reporter gene, $A R G 8^{m}$, fused to the 91 st codon of $C O X 2$. Here we show that three relatively short sequences within the COX2 mRNA coding sequence, or structures they form in vivo, inhibit translation of the reporter in the absence of the positive element. One negative element was localized within codons 15 to 25 and shown to function at the level of the mRNA sequence, whereas two others are within predicted stem-loop structures formed by codons 22-44 and by codons 46-74. All three of these inhibitory elements are antagonized in a sequence-specific manner by reintroduction of the upstream positive-acting sequence. These interactions appear to be independent of 5 '- and 3 '-untranslated leader sequences, as they are also observed when the same reporter constructs are expressed from the COX3 locus. Overexpression of MRS2, which encodes a mitochondrial magnesium carrier, partially suppresses translational inhibition by each isolated negatively acting element, but does not suppress them in combination. We hypothesize that interplay among these signals during translation in vivo may ensure proper timing of pre-Cox2p synthesis and assembly into cytochrome $c$ oxidase.
\end{abstract}

Keywords: Secondary structure; ribosome; cytochrome $c$ oxidase; yeast

\section{INTRODUCTION}

Cytochrome $c$ oxidase is an integral membrane complex consisting of eight nuclear and three mitochondrially encoded subunits in Saccharomyces cerevisiae (Geier et al. 1995). The mitochondrially encoded subunits, Coxlp, Cox $2 p$, and Cox $3 p$, form the enzymatic core. Translation of the three mitochondrial subunits depends upon mRNAspecific activators (Fox 1996a, 1996b), which appear to localize translation within the organelle (Sanchirico et al. 1998). Interactions among these translational activators may facilitate assembly of the enzymatic core by coordinating Coxlp, Cox $2 \mathrm{p}$, and Cox3p synthesis (Naithani et al. 2003).

Translation of the COX2 mRNA encoding subunit II of cytochrome $c$ oxidase is controlled by the rate-limiting ac-

Reprint requests to: Thomas D. Fox, 335 Biotechnology Building, Department of Molecular Biology and Genetics, Cornell University, Ithaca, NY 14853-2703, USA; e-mail: tdf1@cornell.edu.

Article and publication are at http://www.rnajournal.org/cgi/doi/ 10.1261/rna.2182903. tivator Pet111p, which interacts with the 54-nt 5'-untranslated leader of the mRNA (Fox 1996a; Green-Willms et al. 2001). Translation of COX2 yields pre-Cox $2 p$, a precursor protein with a 15-residue leader peptide (Sevarino and Poyton 1980) that is cleaved during or following Cox $2 p$ assembly in the inner membrane (Pratje et al. 1983). Although the leader peptide does not function strictly as a signal sequence directing translocation of a reporter protein fused downstream, it is sufficient to cause association of the fusion protein with the inner membrane (He and Fox 1997). Further, the leader peptide is essential for accumulation of functional Cox $2 p$, as deletion of the leader peptide coding sequence inhibits respiration (Torello et al. 1997). Interestingly, however, mammalian Cox2p is synthesized without a leader peptide (Steffens and Buse 1979; Anderson et al. 1982), and the leader peptide sequences of pre-Cox $2 p$ or other mitochondrial precursor proteins in other fungi (Hardy and Clark-Walker 1990; Hoeben et al. 1993) and in plants (Lu and Hanson 1994) show little similarity to each other.

In addition to a possible role for the leader peptide poly- 
peptide in pre-Cox $2 p$ targeting, the mRNA sequence encoding the leader peptide is required for expression of the reporter $A R G 8^{m}$ (Steele et al. 1996) when it is translationally fused to the 91st codon of COX2 (Bonnefoy et al. 2001). Partial deletions of leader peptide codons from this cox2(191)::ARG $8^{m}$ reporter inhibit its translation (Bonnefoy et al. 2001), despite the fact that the Cox $2 p$ leader peptide is not required for expression of $A R G 8^{m}$ inserted at the COX2 locus in the absence of any COX2 codons (Bonnefoy and Fox 2000). Thus, the leader peptide codons appear to influence translation positively by antagonizing one or more inhibitory sequences within COX2 codons 15 to 91 (Bonnefoy et al. 2001). Characterization of this positive regulatory sequence showed that codons 2 to 6 are most important for activity and that the positive element is embedded within the mRNA sequence, rather than the polypeptide sequence (Bonnefoy et al. 2001).

Here we present the identification and characterization of three inhibitory sequence elements within the Cox $2 p$ coding sequence that inhibit translation in the absence of the positive element embedded in the leader peptide coding sequence. At least one of these elements also appears to be embedded in the nucleotide sequence of the mRNA rather than in the polypeptide sequence it encodes.

\section{RESULTS}

\section{COX2 codons 15-25 are sufficient to inhibit translation of the $A R G 8^{m}$ reporter at $C O X 2$}

Although $A R G 8^{m}$ fused to the first 91 COX2 codons $\left(\operatorname{cox} 2(1-91):: A R G 8^{m}\right)$ is expressed robustly (Bonnefoy and Fox 2000), deletion of COX2 codons 2-14 ( $\operatorname{cox} 2(1,15-$ 91)::ARG $8^{m}$ ) prevents its expression, apparently due to an inhibitory sequence or sequences within the downstream COX2 codons (Bonnefoy et al. 2001). Because the primary translation product coded by this and all other fusion genes used in this study contains the pre-Arg8p matrix protease processing site, mutations introduced upstream of the processing site (within the COX2 codons) do not affect production of mature, processed Arg8p (Bonnefoy and Fox 2000; Bonnefoy et al. 2001), so arginine prototrophy serves as a reliable measure of translational efficiency. To delineate the COX2-encoded inhibitory sequence(s) within cox2(191)::ARG $8^{m}$, we made a series of deletions involving COX2 codons $15-88$ in the context of the codon 2 to 14 deletion and assayed for arginine prototrophy due to restored $A R G 8^{m}$ translation.

An almost complete deletion of the COX2 codons, retaining only the COX2 initiation codon and codons 89-91 ( $\left.\operatorname{cox} 2(1,89-91):: A R G 8^{m}\right)$, produces an $\mathrm{Arg}^{+}$phenotype, as expected. (Codons 89-91 were included in all alleles for cloning purposes.) Seven other mutants retaining variable numbers of codons between 15 and 88 are tightly $\mathrm{Arg}^{-}$(Fig. 1A) and lack detectable Arg8p (Fig. 2 and data not shown), but all accumulate reporter mRNA to levels approximately equal to that of the $\operatorname{Arg}^{+} \operatorname{cox} 2(1,89-91):: A R G 8^{m}$ mutant (Fig. 2 and data not shown), consistent with a defect in translation. Based on these data, codons 15-25, which specify the leader peptide cleavage site and the first 10 residues of mature Cox $2 \mathrm{p}$, are sufficient to inhibit reporter translation.

\section{An inhibitory sequence is largely contained within codons 15-20}

To delineate further the inhibitory sequence within codons 15-25, we deleted single codons sequentially from the $\mathrm{N}$ terminal region (Fig. 1B). All mutants accumulate approximately equal levels of reporter mRNA, and steady-state Arg8p accumulation closely mirrors the observed growth phenotypes on medium lacking arginine (Fig. 2). Overall, these data suggest that an inhibitory sequence lies at the start of the codon 15-25 region, as deletion of codons 15-20 largely restores Arg8p accumulation and arginine prototrophy (Figs. 1B, 2).

The phenotypes of two mutants from the N-to-C deletion series $\left(\operatorname{cox} 2(1,22-25,89-91):: A R G 8^{m}\right.$ and $\operatorname{cox} 2(1,23$ 25,89-91)::ARG $8^{m}$ ) appear inconsistent with the others in the N-to-C deletion series. Furthermore, analysis of single codon deletions from the $\mathrm{C}$ - to the $\mathrm{N}$-terminus indicates that nothing but a complete deletion removes the inhibitory sequence in this region (Fig. 1C). To test whether some deletions generate artifactual inhibitory structures and to identify the sequences responsible for translational inhibition, we attempted to isolate spontaneous, mitochondrially encoded suppressors of nearly all of the auxotrophic or weakly prototrophic strains shown in Figure 1, B and C (Materials and Methods).

Interestingly, only strains bearing alleles cox2(1,15-17, 89-91), $\operatorname{cox} 2(1,15-16,89-91), \operatorname{cox} 2(1,15,89-91), \operatorname{cox} 2(1,22-$ $25,89-91)$, and $\operatorname{cox} 2(1,23-25,89-91):: A R G 8^{m}$ readily yielded $\mathrm{Arg}^{+}$mitochondrial suppressors, as indicated by asterisks in Figure 1. Each suppressor contains a single point mutation, and four out of five of these strains yielded multiple, independent suppressor mutations within a single codon. Additionally, several of the suppressor mutations are silent, implicating the mRNA sequence as the source of translational inhibition. For example, suppressors of $\operatorname{cox} 2(1,15,89$ 91)::ARG $8^{m}$ all alter the asparagine codon corresponding to COX2 codon 15 (Fig. 3A). In the context of predicted mRNA structures, each $\operatorname{cox} 2(1,15,89-91):: A R G 8^{m}$ suppressor destroys a base pair within a novel predicted stemloop structure for that allele (Fig. 3B) that is not predicted for wild type. We obtained similar results from analysis of suppressors of the other suppressible deletions (data not shown). None of the mRNA structures predicted for the five suppressible alleles are similar to structures predicted either for wild-type COX2 or the $\operatorname{cox} 2(1-91):: A R G 8^{m}$ reporter mRNA. We propose that these novel, inhibitory structures 
A

$\operatorname{cox} 2(1-91)$

$\operatorname{cox} 2(1,15-91)$

$\operatorname{cox} 2(1,15-85,89-91)$

$\operatorname{cox} 2(1,15-75,89-91)$

$\operatorname{cox} 2(1,15-65,89-91)$

$\operatorname{cox} 2(1,15-55,89-91)$

$\operatorname{cox} 2(1,15-45,89-91)$

$\operatorname{cox} 2(1,15-35,89-91)$

$\operatorname{cox} 2(1,15-25,89-91)$

$\operatorname{cox} 2(1,89-91)$

B

$\operatorname{cox} 2(1,15-25,89-91)$

$\operatorname{cox} 2(1,16-25,89-91)$

$\operatorname{cox} 2(1,17-25,89-91)$

$\operatorname{cox} 2(1,18-25,89-91)$

$\operatorname{cox} 2(1,19-25,89-91)$

$\operatorname{cox} 2(1,20-25,89-91)$

$\operatorname{cox} 2(1,21-25,89-91)$

$\operatorname{cox} 2(1,22-25,89-91)$

$\operatorname{cox} 2(1,23-25,89-91)$

$\operatorname{cox} 2(1,24-25,89-91)$

$\operatorname{cox} 2(1,25,89-91)$

$\operatorname{cox} 2(1,89-91)$

C

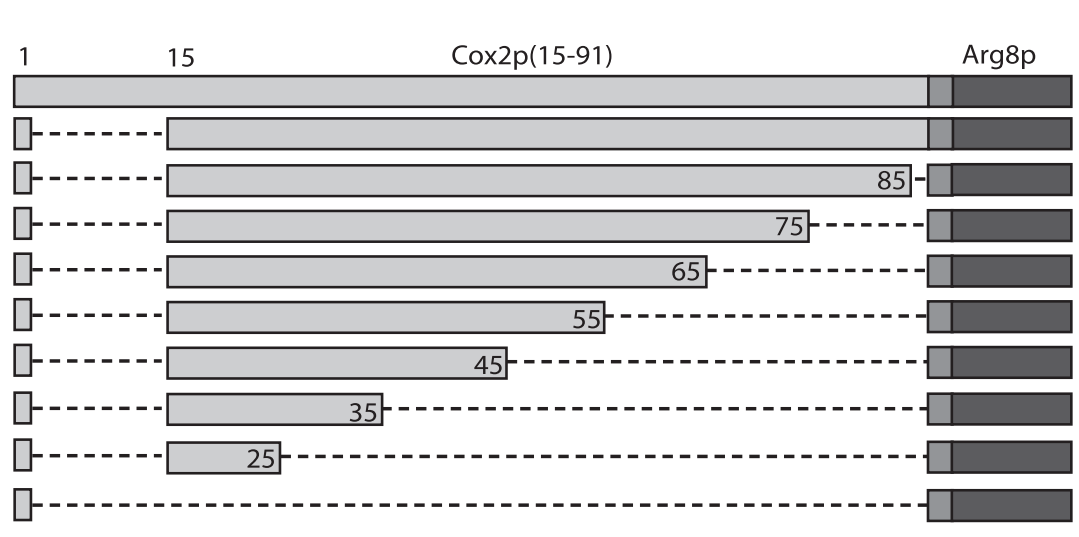

Arg growth +++

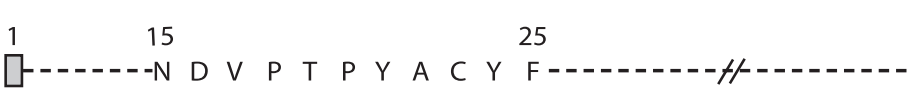
口----DD V P T P Y A C Y F -

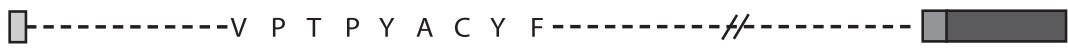

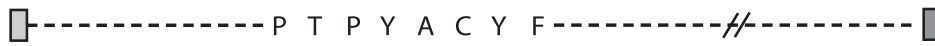
口-1,

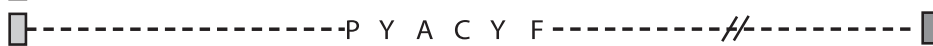

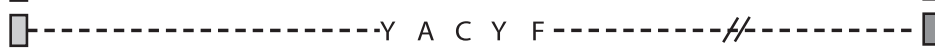
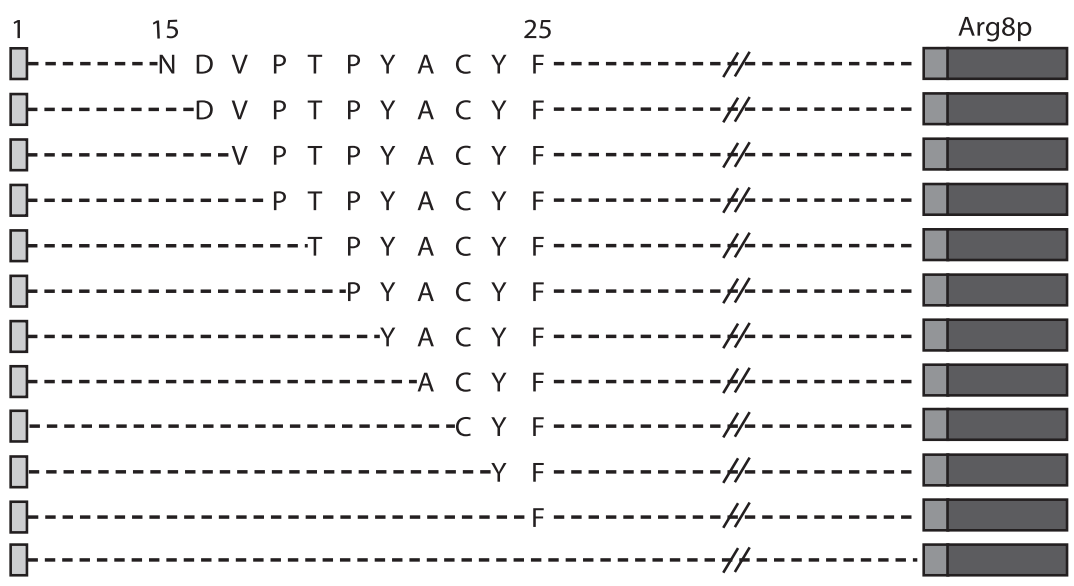

Arg growth

-

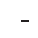

$$
\begin{gathered}
- \\
- \\
- \\
- \\
++ \\
+/- \\
+{ }_{+}^{*} \\
++ \\
+++ \\
+++
\end{gathered}
$$

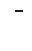

Arg growth

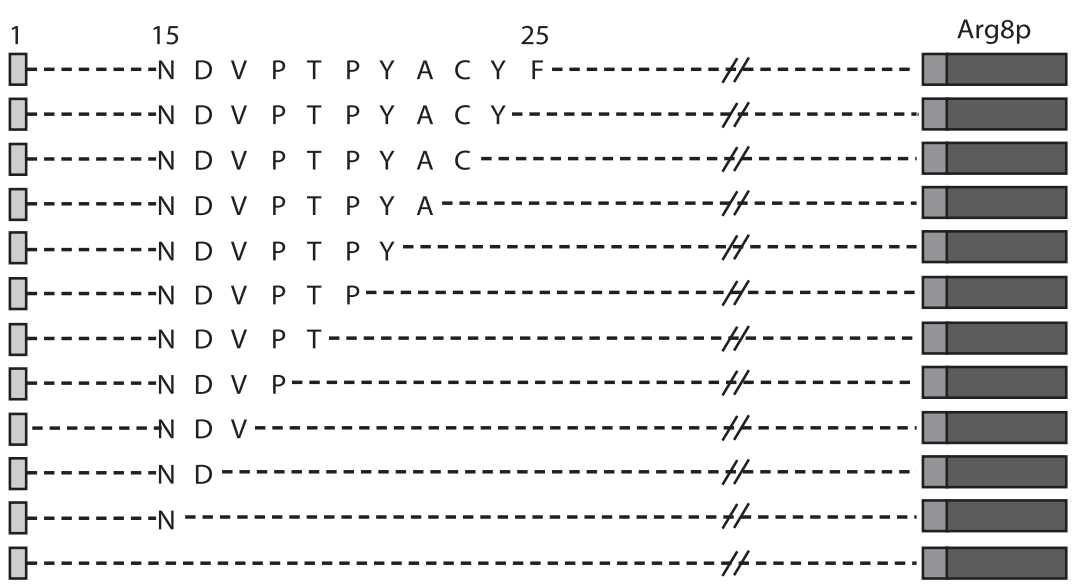

$\operatorname{cox} 2(1,15-25,89-91)$

$\operatorname{cox} 2(1,15-24,89-91)$

$\operatorname{cox} 2(1,15-23,89-91)$

$\operatorname{cox} 2(1,15-22,89-91)$

$\operatorname{cox} 2(1,15-21,89-91)$

$\operatorname{cox} 2(1,15-20,89-91)$

$\operatorname{cox} 2(1,15-19,89-91)$

$\operatorname{cox} 2(1,15-18,89-91)$

$\operatorname{cox} 2(1,15-17,89-91)$

$\operatorname{cox} 2(1,15-16,89-91)$

$\operatorname{cox} 2(1,15,89-91)$

$\operatorname{cox} 2(1,89-91)$

FIGURE 1. Deletions delineate COX2 coding sequence capable of inhibiting translation of downstream $A R G 8^{m}$ in the absence of $C O X 2$ codons 2-14. (A) Deletion constructs consist of variable numbers of COX2 codons 15-88 (light gray boxes), COX2 codons 89-91 (gray boxes), and $A R G 8^{m}$ (dark gray boxes). Dashed lines represent deleted regions. The growth phenotypes of these strains when streaked on medium lacking arginine are shown, with full prototrophy as ".$+++ "$ All strains grow equally well on medium containing arginine (data not shown). Strains shown, from top to bottom: NB43, NB120, and EHW161-EHW154 (Table 1). (B and C) ARG8 ${ }^{m}$, COX2 codons 89-91, and deleted regions are depicted as in $A$. Cox $2 p$ residues coded by each allele within the codon 15-25 region are as written. Strains marked with an asterisk revert to full arginine prototrophy ("+++") by mutation of a single nucleotide. Strains shown from top to bottom in B: EHW155, EHW195-EHW204, and EHW154; and in C: EHW155, EHW185-EHW194, and EHW154 (Table 1).

represent artifacts, and that weakening them is sufficient to restore translation. Reconsidering the N-to-C and C-to-N deletion data in light of the suppressor data, both deletion series indicate that an inhibitory sequence lies largely within codons 15-20 and that removal of these codons is sufficient to restore reporter expression (Fig. 1B,C). 


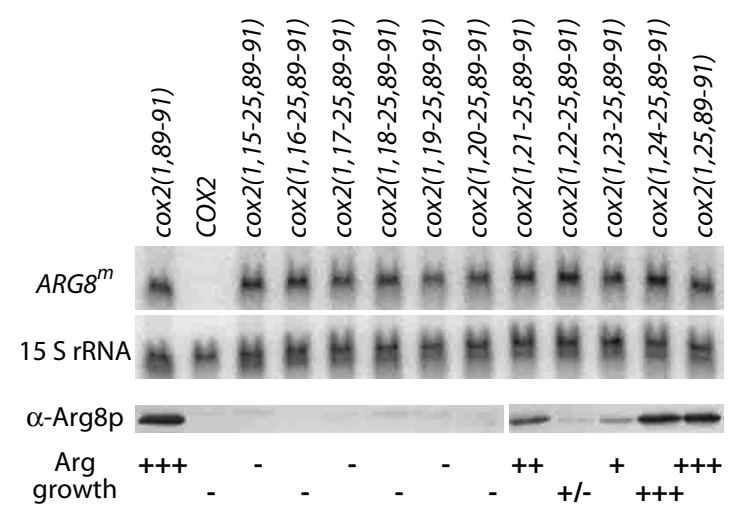

FIGURE 2. Mutations that alter levels of Arg8p reporter protein do not alter steady-state mRNA levels. The top two panels show the results of sequential probing of a Northern blot containing $10 \mu \mathrm{g}$ of total RNA per sample. The blot was probed first with a radioactively labeled probe against $A R G 8^{m}$ (top) and then with a probe against the mitochondrial 15S rRNA (middle) as a loading control. The third panel shows the results of probing a Western blot containing $75 \mu \mathrm{g}$ of total protein per sample with an antibody against Arg8p. The COX2 negative control or $\operatorname{cox} 2:: A R G 8^{m}$ alleles (shown according to the COX2 codons present in the fusion construct) are as written above the top panel, and the respective growth phenotypes are as shown at the bottom of the figure. Strains shown, from left to right: EHW154, NB80, EHW155, and EHW195-EHW204 (Table 1).

\section{The inhibitory element in codons 15-25 is embedded in the mRNA sequence}

We used frameshift mutations and silent substitutions to determine whether the codon 15-25 inhibitory element functions as an mRNA or peptide sequence. First, we altered the peptide sequence dramatically while leaving the mRNA sequence largely unchanged by inserting and deleting single nucleotides flanking codons 15-25 (cox2-230::ARG8 ${ }^{m}$ and $\left.\operatorname{cox} 2-231:: A R G 8^{m}\right) . \mathrm{Arg}^{+}$growth is not restored by the $-1,+1$ frameshift mutation (cox2-231), indicating that the inhibitory element remains intact despite the dramatically changed peptide sequence (Fig. 4). The $+1,-1$ mutation (cox2-230) produces a leaky phenotype, suggesting that the element is weakened by this alteration (Fig. 4). Next, we altered the mRNA while maintaining the encoded peptide sequence by making multiple silent nucleotide substitutions within the codon 15-25 region $\left(\operatorname{cox} 2-232:: A R G 8^{m}\right) . \mathrm{Arg}^{+}$ growth is largely restored by this alteration, suggesting that mutating the nucleotide sequence weakens the inhibitory element (Fig. 4). All three mutants accumulate reporter mRNA to approximately the same level as the translationally competent allele $\operatorname{cox} 2(1,89-91):: A R G 8^{m}$ (data not shown). The tightly $\mathrm{Arg}^{-}-1,+1$ frameshift mutant accumulates no detectable steady-state Arg8p (data not shown), consistent with retention of inhibitory element function. However, the leaky $+1,-1$ frameshift mutant does accumulate detectable Arg8p, to a level actually two- to threefold higher than that of the partially prototrophic recoded mutant. Thus, in contrast to the $-1,+1$ frameshift, the $+1,-1$ frameshift substantially weakens the element. We believe the discrepancy between Arg8p level and growth phenotype for the $+1,-1$ mutant may reflect a defect in a posttranslational step in Arg8p maturation due to the unnatural Nterminal sequence encoded by this allele. Despite this anomaly, the consistency of the phenotypes for the $-1,+1$ frameshift and recoded mutants strongly suggests that the codon 15-25 element functions at the level of the mRNA sequence, rather than the peptide sequence.

\section{Elevated dosage of MRS2, which encodes a mitochondrial $\mathrm{Mg}^{++}$carrier, promotes translation through the codon 15-25 inhibitory element}

To characterize further the mechanism by which the codon 15-25 inhibitory sequence reduces translation, we screened for genes that, when overexpressed, allowed a $\operatorname{cox} 2(1,15$ 25,89-91)::ARG $8^{m}$ strain to grow in the absence of arginine (Materials and Methods). Three genes were recoveredMRS2, TIF3, and CAR2 (Fig. 5 and data not shown).

MRS2 encodes a mitochondrial inner membrane protein that functions as a magnesium transporter (Bui et al. 1999; Gregan et al. 2001) and is required for splicing of mito-

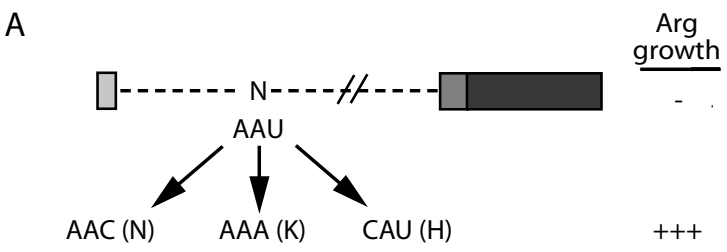

B

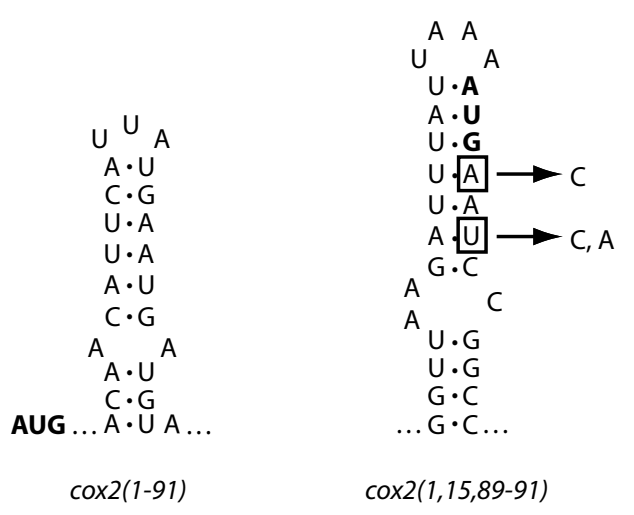

FIGURE 3. Translational inhibition by a single COX2 codon is apparently due to an artifactual secondary structure created by the deletion mutation. (A) $A R G 8^{m}$, COX2 codons 89-91, and deleted regions of $\operatorname{cox} 2(1,15,89-91):: A R G 8^{m}$ are diagrammed as in Figure 1. Three unique suppressors of this strain, which all fall within codon 15 , are shown, as well as the resulting residue encoded. (B) One predicted mRNA structure for a portion of the fully prototrophic cox2(191)::ARG $8^{m}$ allele is shown, as is a predicted structure for $\operatorname{cox} 2(1,15$, 89-91)::ARG ${ }^{m}$. Each initiation codon is shown in bold. Nucleotides mutated in the $\operatorname{cox} 2(1,15,89-91):: A R G 8^{m}$ suppressors are boxed, and the resulting nucleotides are shown to the right. 


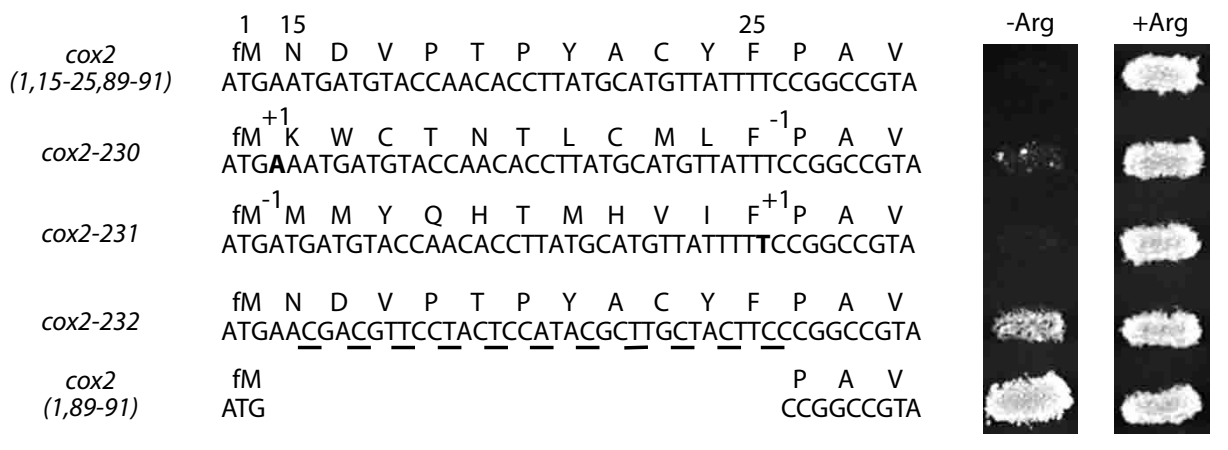

FIGURE 4. Inhibition of translation by codons $15-25$ is more dependent upon the mRNA sequence than the encoded peptide sequence. Nucleotide and peptide sequences for the COX2 portions of $\operatorname{cox} 2(1,15-25,89-91):: A R G 8^{m}$ and three derivative alleles, as well as for the prototrophic allele $\operatorname{cox} 2(1,89-91):: A R G 8^{m}$, and phenotypes are shown. $\operatorname{cox} 2-230:: A R G 8^{m}$ and $\operatorname{cox} 2-231:: A R G 8^{m}$ shift the reading frame for codons $15-25$ into the +1 and -1 frames, respectively. Inserted nucleotides are shown in bold, and the positions of insertions and deletions are denoted as " +1 " and " -1 ." The third allele, cox2-232::ARG8 ${ }^{m}$, introduces silent third nucleotide substitutions (underlined) into each codon in this region. Strains shown, from top to bottom: EHW155, EHW328-EHW330, and EHW154 (Table 1).

chondrial group II introns (Wiesenberger et al. 1992; Waldherr et al. 1993; Schmidt et al. 1998). $\operatorname{cox} 2(1,15-25,89$ 91)::ARG $8^{m}$ contains no introns, so suppression likely is not due to an effect on splicing. Interestingly, however, MRS2 overproduction has been shown to increase mitochondrial magnesium concentration (Bui et al. 1999; Gregan et al. 2001), which could dramatically alter mRNA folding and/or ribosomal function, and thereby improve translation of the mutant mRNA.

TIF3 encodes cytoplasmic initiation factor eIF4B, which facilitates unfolding of complex mRNA structures in concert with eIF4A both in vitro and in cytoplasmic translation in vivo (Altmann et al. 1995; Bi et al. 2000; Rogers et al. 2001). TIF3 dosage suppression in this system could be either direct or indirect: eIF4B/eIF4A imported into mitochondria may facilitate reporter translation directly, or cytoplasmic eIF4B/eIF4A may increase reporter translation through quantitative effects on the expression of unknown cytoplasmic factors. To address this uncertainty, we targeted eIF4B to the mitochondrial matrix by fusing it to the matrix localization signal of pre-Cox4p (Materials and Methods; Pinkham et al. 1994). Neither single copy nor high copy genes encoding mitochondrially targeted eIF4B suppress (data not shown), arguing against a direct effect of eIF4B on mitochondrial translation.

CAR2 encodes ornithine oxo-acid aminotransferase, an enzyme normally responsible for degradation of arginine, ornithine, and citrulline (Jauniaux et al. 1978). The seemingly contradictory $\mathrm{Arg}^{+}$phenotype observed here may be due to misregulation of the enzyme under overexpression conditions. Because $\mathrm{Arg}^{+}$growth in the presence of CAR2 does not require the presence of mitochondrial DNA (data not shown), suppression must be due to a metabolic rather than translational mechanism.

We also asked whether increased dosage of the gene
The positive regulatory element encoded within codons 2-6 specifically overcomes inhibition by the codon 15-25 inhibitory sequence

To study interaction between the codon 15-25 element in $\operatorname{cox} 2(1,15-25,89-91):: A R G 8^{m}$ and the upstream positive element (Bonnefoy et al. 2001), we tested whether reintroduction of the leader peptide coding sequence (codons 2-14) into $\operatorname{cox} 2(1,15-25,89-91):: A R G 8^{m}$ allowed reporter translation, as evidenced by arginine prototrophy. We found that it did (Fig. 6). To ask whether $\mathrm{Arg}^{+}$growth is due to specific action of the positive element or simply due to insertion of a spacer element between the initiation codon and the inhibitory sequence, we introduced wildtype codons 2-6, which encode much of the positive element within the leader peptide (Bonnefoy et al. 2001), and a version of codons 2-6 containing multiple silent mutations that inactivate the positive element (Bonnefoy et al. 2001). Only the five codons containing a functional positive element restore growth (Fig. 6), strongly suggesting that the positive element actively antagonizes translational inhibition caused by codons 15-25.

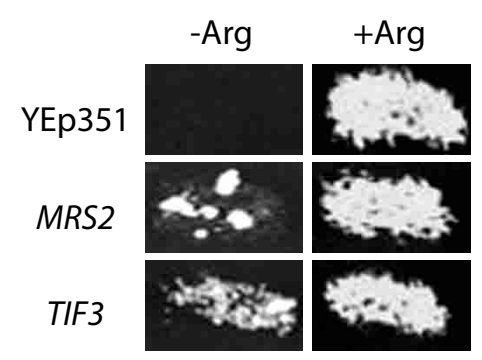

FIGURE 5. Elevated dosage of MRS2 and TIF3 allows translation of the $\operatorname{cox} 2(1,15-25,89-91):: A R G 8^{m}$ reporter and $\mathrm{Arg}^{+}$growth. The empty vector Yep351 serves as a negative control. 


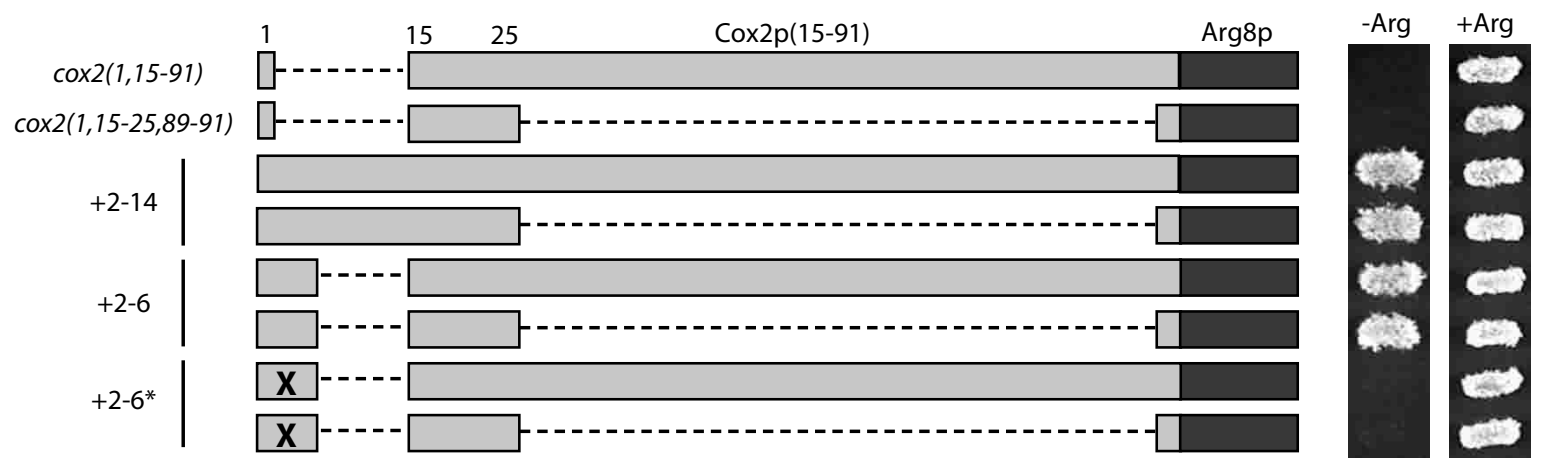

FIGURE 6. The positive element encoded within the mRNA specifying the pre-Cox $2 p$ leader peptide antagonizes translational inhibition by codons 15-25. Starting with $\operatorname{cox} 2(1,15-91):: A R G 8^{m}$ (Bonnefoy et al. 2001) and $\operatorname{cox} 2(1,15-25,89-91):: A R G 8^{m}$, as diagrammed at the top of the figure, alleles were created that reintroduce codons $2-14$, which encode the full leader peptide (" $+2-14$ "); codons 2-6, which encode much of the positive element ("+2-6"; Bonnefoy et al. 2001); or a derivative of codons 2-6 in which the mRNA sequence has been altered, which leaves the positive element nonfunctional (" $+2-6^{*}$ "; Bonnefoy et al. 2001). ARG $8^{m}$, COX2 codons, and deleted regions are diagrammed as in Figure 1. Strains shown, from top to bottom: NB120, EHW155, NB43, EHW380, NB135, EHW383, NB179, and EHW384 (Table 1).

\section{The codon 15-25 inhibitory element can act independently of other COX2 regulatory sequences}

To ask whether translational inhibition by codons $15-25$ depends upon COX2 regulatory sequences, such as the $5^{\prime}$ UTL of the mRNA, we created three chimeric alleles in which derivatives of the $\operatorname{cox} 2:: A R G 8^{m}$ reporter were placed into the $C O X 3$ locus and therefore under the control of COX3 untranslated sequences. Mutants containing a complete replacement of $C O X 3$ coding sequences with $A R G 8^{m}$ or with $\operatorname{cox} 2(1,89-91):: A R G 8^{m}$ (cox3 $\triangle:: A R G 8^{m}$ and $\operatorname{cox} 3-41$, respectively) are strongly $\mathrm{Arg}^{+}$(Fig. 7). However, inclusion of codons 15-25 upstream of the reporter (cox3-42) dramatically inhibits translation, as for the analogous allele at COX2, which confirms that no sequence outside of codons 15-25 is required for inhibitory element function. Reporter
mRNA levels are equivalent for all three constructs, and steady-state Arg8p accumulation is consistent with the observed growth phenotypes (data not shown).

To test whether translational inhibition of $\operatorname{cox} 2(1,15$ 25,89-91)::ARG $8^{m}$ at COX2 and COX3 was due to the same mechanism, we assayed whether the COX3-derived allele responds to MRS2 and TIF3 overexpression and whether the $C O X 2$ leader peptide coding sequence can antagonize translational inhibition at $C O X 3$. As shown in Figure 7, high copy plasmids bearing TIF3 and MRS2 and functional forms of the leader peptide-encoded positive element restore $\mathrm{Arg}^{+}$growth, whereas the nonfunctional leader peptide allele does not. Therefore, translational inhibition by codons 15-25 at COX2 and COX3 appears to occur through a similar mechanism and does not require COX2 mRNA untranslated sequences.

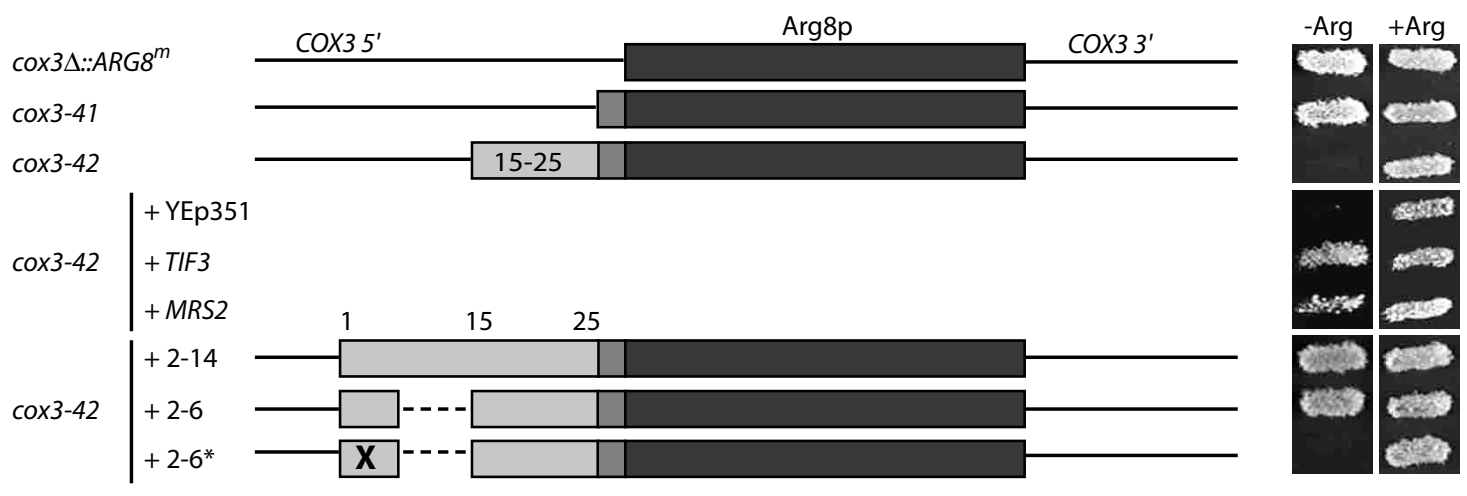

FIGURE 7. Codons 15-25 inhibit translation independently of COX2 mRNA untranslated sequences. Codons 15-25 were introduced with the $A R G 8^{m}$ reporter at the COX3 locus. cox $3 \Delta:: A R G 8^{m}$ completely replaces COX3 coding sequences with those of $A R G 8^{m}$; $\operatorname{cox} 3-41$ inserts only the COX2 codon 89-91 linker between the initiation codon and the $A R G 8^{m}$ reporter; and cox3-42 is like cox3-41 plus the insertion of COX2 codons 15-25. ARG ${ }^{m}, C O X 2$ codons, and deleted regions are diagrammed as in Figure 1. Suppression of translational inhibition by codons 15-25 at COX3 was assayed in strains overexpressing TIF3 or MRS2 ("+TIF3" and "+MRS2") compared to a strain transformed with empty vector alone ("+YEp351"). Suppression of translational inhibition at the COX3 locus also was assayed by introduction of the full COX2 leader peptide (“+2-14"), of much of the positive element within codons 2-6 (“+2-6"; Bonnefoy et al. 2001), or of five altered codons (“+2-6*”; Bonnefoy et al. 2001). Strains shown, from top to bottom: EHW334-EHW336 and EHW391-EHW393 (Table 1). 


\section{Additional inhibitory sequences are encoded downstream from the codon 15-25 element}

We predicted that deleting both the positive-acting and inhibitory elements within COX2 codons 1-91 would allow reporter translation, as $A R G 8^{m}$ is expressed efficiently in the absence of any COX2 codons (Bonnefoy and Fox 2000). However, a mutant deleted for both the positive element within the leader peptide coding region and for the codon 15-25 element (cox2[1,26-91]::ARG $8^{m}$ ) is $\mathrm{Arg}^{-}$, which suggested the existence of additional inhibitory sequence(s) within codons 26-91. Consistent with the idea that multiple inhibitory sequences lie within codons 15-91, elevated dosage of MRS2 and TIF3 does not yield $\mathrm{Arg}^{+}$growth in a mutant lacking the positive element but containing codons 15-91 (cox2[1,15-91]::ARG8 ${ }^{m}$; Bonnefoy et al. 2001; data not shown). We investigated the downstream element(s), guided largely by mRNA structure predictions (mfold 3.0 at http://bioinfo.math.rpi.edu/ mfold/rna/form1-2.3.cgi). These predictions suggest the presence of two large stem-loop structures in the region: one encompassing codon 22 through the first nucleotide of codon 45, and the other encompassing codon 46 through the upstream 2 nt of codon 74. These will be referred to as the codon $22-44$ and 46-74 inhibitory elements.

In analogous experiments to those described for analyzing the codon 15-25 sequence, the codon 22-44 and 46-74 elements were tested for dependence on COX2 coding or regulatory sequences for function, for dosage suppression by MRS 2 and TIF3, and for suppression by reintroduction of the positive element. The codon 22-44 and codon 46-74 sequence elements are each sufficient to inhibit translation of $A R G 8^{m}$ at both the COX2 and COX3 loci in the absence of other COX2 coding or regulatory sequences (Fig. 8A). Although MRS2 or TIF3 overproduction does not allow translation of mRNAs containing two or three elements together (such as in $\operatorname{cox} 2[1,15-91]:: A R G 8^{m}$ ), overexpression of either ORF is sufficient to suppress translational inhibition by these sequence elements when present singly at the COX2 locus (data not shown). Also, as was observed for the codon 15-25 element, reintroduction of a functional positive element (in codons 2-14 or 2-6) is both necessary and sufficient to overcome inhibition by either of these downstream elements when present individually (Fig. 8B) or when present together in $\operatorname{cox} 2(1,26-91):: A R G 8^{m}$ (data not shown). All strains used to analyze the downstream elements accumulate wild-type levels of reporter mRNA and steady-state Arg8p at levels consistent with their growth phenotypes (data not shown). Thus, both the codon 22-44 and codon 46-74 elements behave as discrete sequence elements capable of inhibiting translation in the absence of the antagonistic positive element.

We also obtained two independent suppressors of $\operatorname{cox} 2(1,46-75,89-91):: A R G 8^{m}$ that, with additional analysis,

A
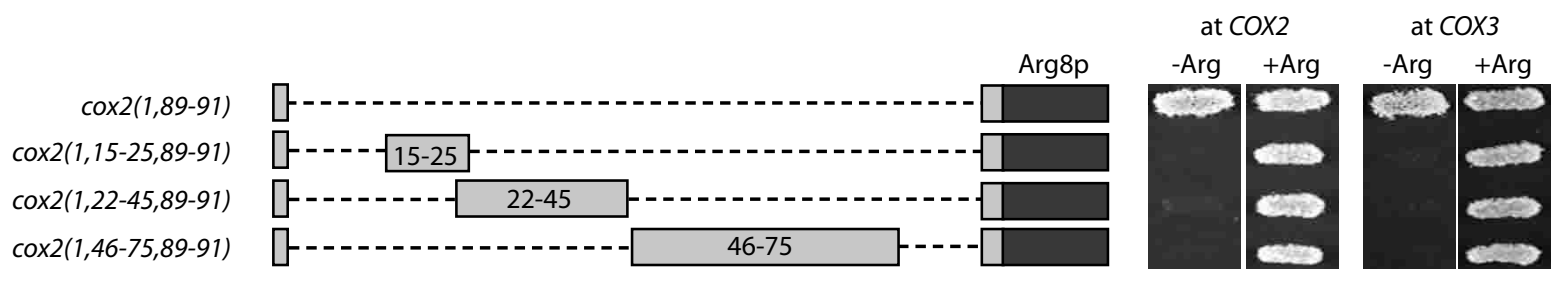

B
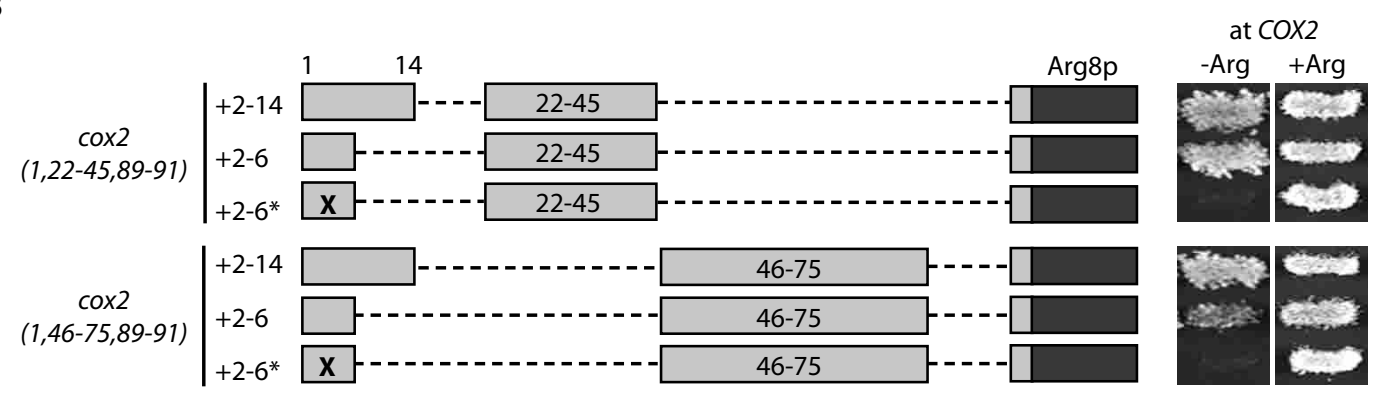

FIGURE 8. Two additional downstream inhibitory elements can inhibit $A R G 8^{m}$ translation at both the COX2 and COX3 loci and are suppressed by the presence of the positive element within the COX2 leader peptide coding sequence. $(A)$ Constructs were created as shown in which either codons 22-45, which contain the predicted codon 22-44 stem-loop, or codons 46-75, which contain the predicted codon 46-74 stem-loop, were isolated from other COX2 coding sequences and inserted either at the COX2 or COX3 locus. ARG $8^{m}$, COX2 codons, and deleted regions are diagrammed as in Figure 1. Growth of control prototrophic $\left(\operatorname{cox} 2(1,89-91):: A R G 8^{m}\right)$ and auxotrophic $\left(\operatorname{cox} 2(1,15-25,89-91):: A R G 8^{m}\right)$ strains on medium containing (+Arg) or lacking (-Arg) arginine are shown at the top for comparison. Strains shown, from top to bottom: at COX2: EHW154, EHW155, EHW358, and EHW357; and at COX3: EHW335, EHW336, EHW378, and EHW379 (Table 1). (B) The full leader peptide coding sequence ("+2-14"), only codons 2-6 encoding much of the positive element ("+2-6"; Bonnefoy et al. 2001), or an inactive version of the positive element within codons 2-6 ("+2-6*"; Bonnefoy et al. 2001) were introduced in front of the isolated codon 22-44 and 46-74 inhibitory sequences at COX2. ARG8 ${ }^{m}, C O X 2$ codons, and deleted regions are diagrammed as in Figure 1. Strains shown, from top to bottom: EHW412-EHW414 and EHW409-EHW411 (Table 1). 
may be informative as to the mechanism of action of this inhibitory element. Both suppressors encode the same missense mutation in COX2 codon 52 (GGT to AGT) and are fully $\mathrm{Arg}^{+}$(data not shown). This mutation disrupts a G-C base pair within the predicted codon 46-74 stem-loop and dramatically destabilizes the structure, which suggests that mRNA unfolding may be sufficient to restore translation. Alternatively, mutation of residue 52 from glycine to serine could dramatically inhibit a polypeptide-based regulatory system.

\section{DISCUSSION}

We have shown that relatively short sequences within the COX2 mRNA coding sequence, or the structures they form in vivo, can inhibit translation of a translationally fused reporter mRNA. These effects appear to be independent of $5^{\prime}$ - and $3^{\prime}$-untranslated leader sequences, as they are observed when the same reporter constructs are expressed from the COX3 locus. We identified three such inhibitory sequences in the COX2 mRNA using deletion analyses: one contained within codons 15-25 (further localized largely to codons 15-20) and shown to function at the level of the mRNA sequence, and two further downstream within predicted stem-loop structures (one encompassing codons 2244 and one encompassing codons 46-74). In the wild-type COX2 mRNA, all three of these inhibitory elements are antagonized by the upstream positive element located in the leader peptide coding region (codons 2-14; Bonnefoy et al. 2001).

We focused on the inhibitory element contained within codons 15-25, which encode the leader peptide cleavage site $(\mathrm{N}-\mathrm{D})$ and the next nine residues of mature Cox $2 \mathrm{p}$. Codons 15-25 are sufficient to inhibit translation of $A R G 8^{m}$ at COX2 in the absence of other COX2 coding sequences and at $C O X 3$ in the absence of $C O X 2$ coding or regulatory sequences. Thus, this element does not require interaction with untranslated regions. This element apparently functions at the level of the mRNA sequence based on the behavior of frameshift and silent substitution mutations. However, the element may be sensitive to the reading frame in which it is placed. Shifting codons 15-25 into the +1 frame partially destroyed inhibitory activity, whereas shifting into the -1 frame did not. Differences in the efficiency of translational pausing due to the reading frame in which a given mRNA structure is encountered have been observed in studies of eukaryote cytosolic ribosomes, using either the minimal infectious bronchitis virus frameshifter pseudoknot or a synthetic stem-loop structure inserted $\sim 1200 \mathrm{nt} 3^{\prime}$ of the start codon of a reporter mRNA as templates in rabbit reticulocyte and wheat germ in vitro systems (Kontos et al. 2001). A similar frame-dependent effect on the efficiency of mitochondrial ribosomal pausing at the codon 15-25 element could account for the phenotypes observed here, although it is also possible that the $+1,-1$ mutation affected the mRNA structure more than the $-1,+1$ mutation.

Overexpression of MRS2, which encodes a mitochondrial magnesium carrier (Bui et al. 1999; Gregan et al. 2001), partially suppresses translational inhibition by the codon 15-25 element. Under overexpression conditions, magnesium concentrations are increased in the matrix (Gregan et al. 2001), so dosage suppression of the codon 15-25 element translational inhibition by MRS2 is likely related to this increase in mitochondrial magnesium concentration. Magnesium and other divalent cations interact with RNA and affect the stability of tertiary structures, through both diffuse binding along the phosphate backbone and through site-specific binding to nucleotide and/or phosphate atoms (Misra and Draper 1998). Clearly such effects on the COX2 mRNA could weaken the translational blocks caused by the internal inhibitory elements. Alternatively, however, properties of the mitochondrial translation system could be altered by increased magnesium concentrations such that it is able to traverse the inhibitory elements more efficiently.

We also isolated TIF3 (eIF4B) as a dosage-dependent suppressor of translational inhibition by the codon 15-25 element. This effect appears to be indirect, because suppression is lost when eIF4B is deliberately targeted to the mitochondrial matrix. Consistent with this idea, two other examples of indirect effects on mitochondrial gene expression by altered dosage of genes encoding cytoplasmic translation factors have been reported previously (Linder and Slonimski 1989; Folley and Fox 1994). Presumably these dosage effects are due to quantitative changes affecting cytoplasmic mRNA translation, which in turn alter the function of the mitochondrial translation system. Similarly, an indirect dosage effect likely explains suppression we observed in spontaneous aneuploid suppressors selected from a cox2(1,15-25,89-91)::ARG8 ${ }^{m}$ strain (E.H. Williams, unpubl.).

Several pieces of evidence suggest that multiple COX2 (and $\operatorname{cox} 2:: A R G 8^{m}$ ) secondary structures regulate translation. Inhibition of translation by small deletions within the leader peptide can be relieved by mutations that weaken predicted stem-loop structures immediately downstream of the deletions, in the region encoding the pre-Cox $2 p$ cleavage site (Bonnefoy et al. 2001). Some of these suppressor mutations fall within the codon 15-25 element, suggesting that mutation of this inhibitory sequence, or the stem-loops into which it folds in these strains, alleviates the translational inhibition. Furthermore, in structure predictions for wild-type COX2, a similar stem-loop forms such that codons 15-17 pair with codons 10-14, which encode the downstream portion of the leader peptide and which are important to the function of the positive element (Bonnefoy et al. 2001). If this stem-loop structure exists in vivo, then interaction of the codon 15-25 element with the positive element may control wild-type COX2 translation, consistent with the data presented here. 
Additionally, a predicted stem-loop structure within the COX2 mRNA 5'-untranslated leader interacts genetically with the COX2-specific translational activator Pet111p (Dunstan et al. 1997) and with the mitochondrial ribosomal small subunit proteins Mrp21p and Mrp51p (Green-Willms et al. 1998). In vitro dimethyl sulfate modification experiments revealed protection of one residue within this predicted stem-loop structure, confirming its existence (Papadopoulou et al. 1990). Although overproduction of Pet111p increases the rate of COX2 mRNA translation (GreenWillms et al. 2001), it does not lead to detectable translation through the inhibitory elements reported here.

We screened extensively for mitochondrial mutations that allowed translation through the codon 15-25 element, both in the $\operatorname{cox} 2(1,15-25,89-91):: A R G 8^{m}$ allele and in its partial deletion derivatives. The only mitochondrial suppressor we obtained, however, was a bypass suppressor containing wild-type mtDNA present heteroplasmically with a genomically rearranged $\rho^{-}$mtDNA molecule (Müller et al. 1984). This rearrangement of $\operatorname{cox} 2(1,15-25,89-91):: A R G 8^{m}$ mtDNA deleted COX2 codons 15-25 and replaced them with upstream regulatory and some coding sequences from ATP9, which allowed translation of the downstream reporter (E.H. Williams, unpubl.). This result confirms that removal of these COX2 codons is sufficient to restore reporter translation. Other than by deletion, we were only able to restore reporter translation in the presence of codons $15-25$ by introducing multiple third nucleotide substitutions into the codon 15-25 region, which confirms that this element is robust and contains multiple contributing nucleotides. In contrast, we readily obtained point mutations that weakened novel (i.e., not present in the wild-type sequence), and presumably artifactual, predicted secondary structures generated by some of our deletion mutations and restored translation through them. These results confirm that yeast mitochondrial ribosomes are sensitive to secondary structures within coding sequences, as are yeast cytoplasmic ribosomes (Baim et al. 1985).

Additional sequences downstream of the codon 15-25 inhibitory element are capable of inhibiting translation of the $A R G 8^{m}$ reporter when the leader peptide encoded positive element is absent. Two such elements were preliminarily delineated within codons $22-44$ and 46-74 and may function as mRNA-encoded elements through large predicted stem-loop structures. However, further analysis is necessary to characterize both of these elements.

We do not know how these antagonistic signals within the COX2 mRNA function and interact with each other, nor do we know the biological rationale of this translational control system. We speculate that the positive element could function specifically and cotranslationally to overcome each inhibitory sequence, possibly by interacting with proteins that facilitate translation through inhibitory elements. A translating $S$. cerevisiae mitochondrial ribosome would be expected to shield 30-35 nt of mRNA, based on the model for the Thermus thermophilus 70S ribosome (Yusupova et al. 2001). If this is the case, the COX2 mRNA $5^{\prime}$-untranslated leader and its first 4 to 10 codons, which encode much of the positive element, would be exposed outside a ribosome paused within the codon 15-25 inhibitory element. In such a state, the exposed mRNA encoding the positive element could bind to an unknown protein factor, which in turn could alter the ribosome and/or the downstream COX2 mRNA and facilitate translation through the inhibitory sequence elements.

Translational regulation mediated by ribosomal pausing due to mRNA secondary structure and codon usage has long been thought to play a role in the regulation of protein folding and assembly (Thanaraj and Argos 1996), and translational control mediated by ribosomal pausing due to socalled effector motifs in nascent polypeptides is well established at both the biochemical and structural level (for reviews, see Sachs and Geballe 2002; Tenson and Ehrenberg 2002). Ribosomal pausing in one such example utilizing an effector motif, that of the SecM-SecA regulatory system for the Escherichia coli SecYEG protein export complex, involves translation of the polycistronic secM-secA mRNA. When SecM is translated but exported inefficiently because of low levels of the SecA-SecYEG complex, cotranslational ribosomal pausing at the effector motif encoded within the $3^{\prime}$ end of the secM coding sequence facilitates unwinding of a downstream mRNA secondary structure, which unmasks the $\sec A$ initiation codon and in turn leads to synthesis of SecA (McNicholas et al. 1997; Oliver et al. 1998; Nakatogawa and Ito 2001). This feedback system therefore ensures an optimized level of SecA synthesis and highly efficient protein export. It is appealing to hypothesize that cytochrome $c$ oxidase assembly could utilize a similar feedback system, such that ribosomal pausing during pre-Cox $2 p$ synthesis allows monitoring of whether mitochondrial conditions are appropriate for synthesis and assembly of preCox $2 \mathrm{p}$, and perhaps other cytochrome $c$ oxidase subunits, into a mature cytochrome $c$ oxidase complex. This hypothesis for regulation by the nascent polypeptide is particularly appealing for the codon 46-74 inhibitory element we have described, because a ribosome paused at the codon 46-74 inhibitory sequence would have synthesized enough nascent polypeptide for the leader peptide to be emerging from the exit channel, if predictions of channel length in E. coli ribosomes (Picking et al. 1992) hold for yeast mitochondrial ribosomes. Continued synthesis of pre-Cox $2 p$ then could be dependent on interaction of the signal sequence with factors necessary for membrane insertion prior to synthesis of the first Cox $2 p$ transmembrane domain.

In summary, we describe here the identification and characterization of three inhibitory sequence elements located within the yeast mitochondrial COX2 coding sequence or the pre-Cox $2 \mathrm{p}$ polypeptide. In our reporter system, these three elements antagonize the previously identified positive element contained within the mRNA encoding 
TABLE 1. S. cerevisiae strains used in this study

\begin{tabular}{|c|c|c|}
\hline Strain name ${ }^{\mathrm{a}}$ & COX 2 or $C O X 3$ allele & Source or reference \\
\hline \multicolumn{3}{|c|}{ Strains isogenic or congenic to DBY $947^{b}$} \\
\hline DFS160 $\rho^{\circ}$ & & Steele et al. (1996) \\
\hline NB63 & $\operatorname{cox} 2-107$ & Bonnefoy and Fox (2000) \\
\hline NB71 & $\operatorname{cox} 3:: \arg 8^{m}-1$ & Bonnefoy and Fox (2000) \\
\hline \multicolumn{3}{|c|}{ Strains isogenic or congenic to D273-10B } \\
\hline NB40-3C & $\cos 2-62$ & Bonnefoy and Fox (2000) \\
\hline NB43 & $\operatorname{cox} 2(1-91):: A R G 8^{m}$ & Bonnefoy and Fox (2000) \\
\hline NB80 & $\operatorname{COX} 2$ & Bonnefoy and Fox (2000) \\
\hline NB120 & $\operatorname{cox} 2(1,15-91):: A R G 8^{m}$ & Bonnefoy et al. (2001) \\
\hline NB135 & $\operatorname{cox} 2(1-6,15-91):: A R G 8^{m}$ & Bonnefoy et al. (2001) \\
\hline NB179 & $\operatorname{cox} 2\left(1,2-6^{*}, 15-91\right):: A R G 8^{m d}$ & Bonnefoy et al. (2001) \\
\hline NSG171 $\rho^{\text {oe }}$ & COX2 & N.S. Green-Willms (unpubl.) \\
\hline EHW154 & $\operatorname{cox} 2(1,89-91):: A R G 8^{m}$ & This study \\
\hline EHW155 & $\operatorname{cox} 2(1,15-25,89-91):: A R G 8^{m}$ & This study \\
\hline EHW156 & $\operatorname{cox} 2(1,15-35,89-91):: A R G 8^{m}$ & This study \\
\hline EHW157 & $\operatorname{cox} 2(1,15-45,89-91):: A R G 8^{m}$ & This study \\
\hline EHW158 & $\operatorname{cox} 2(1,15-55,89-91):: A R G 8^{m}$ & This study \\
\hline EHW159 & $\operatorname{cox} 2(1,15-65,89-91):: A R G 8^{m}$ & This study \\
\hline EHW160 & $\operatorname{cox} 2(1,15-75,89-91):: A R G 8^{m}$ & This study \\
\hline EHW161 & $\operatorname{cox} 2(1,15-85,89-91):: A R G 8^{m}$ & This study \\
\hline EHW185 & $\operatorname{cox} 2(1,15-24,89-91):: A R G 8^{m}$ & This study \\
\hline EHW186 & $\operatorname{cox} 2(1,15-23,89-91):: A R G 8^{m}$ & This study \\
\hline EHW187 & $\operatorname{cox} 2(1,15-22,89-91):: A R G 8^{m}$ & This study \\
\hline EHW188 & $\operatorname{cox} 2(1,15-21,89-91):: A R G 8^{m}$ & This study \\
\hline EHW189 & $\operatorname{cox} 2(1,15-20,89-91):: A R G 8^{m}$ & This study \\
\hline EHW190 & $\operatorname{cox} 2(1,15-19,89-91):: A R G 8^{m}$ & This study \\
\hline EHW191 & $\operatorname{cox} 2(1,15-18,89-91):: A R G 8^{m}$ & This study \\
\hline EHW192 & $\operatorname{cox} 2(1,15-17,89-91):: A R G 8^{m}$ & This study \\
\hline EHW193 & $\operatorname{cox} 2(1,15-16,89-91):: A R G 8^{m}$ & This study \\
\hline EHW194 & $\operatorname{cox} 2(1,15,89-91):: A R G 8^{m}$ & This study \\
\hline EHW195 & $\operatorname{cox} 2(1,16-25,89-91):: A R G 8^{m}$ & This study \\
\hline EHW196 & $\operatorname{cox} 2(1,17-25,89-91):: A R G 8^{m}$ & This study \\
\hline EHW197 & $\operatorname{cox} 2(1,18-25,89-91):: A R G 8^{m}$ & This study \\
\hline EHW198 & $\operatorname{cox} 2(1,19-25,89-91):: A R G 8^{m}$ & This study \\
\hline EHW199 & $\operatorname{cox} 2(1,20-25,89-91):: A R G 8^{m}$ & This study \\
\hline EHW200 & $\operatorname{cox} 2(1,21-25,89-91):: A R G 8^{m}$ & This study \\
\hline EHW201 & $\operatorname{cox} 2(1,22-25,89-91):: A R G 8^{m}$ & This study \\
\hline EHW202 & $\operatorname{cox} 2(1,23-25,89-91):: A R G 8^{m}$ & This study \\
\hline EHW203 & $\operatorname{cox} 2(1,24-25,89-91):: A R G 8^{m}$ & This study \\
\hline EHW204 & $\operatorname{cox} 2(1,25,89-91):: A R G 8^{m}$ & This study \\
\hline EHW328 & $\operatorname{cox} 2-230:: A R G 8^{m}$ & This study \\
\hline EHW329 & $\operatorname{cox} 2-231:: A R G 8^{m}$ & This study \\
\hline EHW330 & $\operatorname{cox} 2-232:: A R G 8^{m}$ & This study \\
\hline EHW $334^{f}$ & $\operatorname{cox} 3 \Delta:: A R G 8^{m}$ & This study \\
\hline EHW $335^{f}$ & $\cos 3-41$ & This study \\
\hline EHW $336^{\mathrm{f}}$ & $\cos 3-42$ & This study \\
\hline EHW357 & $\operatorname{cox} 2(1,46-75,89-91):: A R G 8^{m}$ & This study \\
\hline EHW358 & $\operatorname{cox} 2(1,22-45,89-91):: A R G 8^{m}$ & This study \\
\hline EHW $378^{f}$ & $\cos 3-43$ & This study \\
\hline EHW $379^{f}$ & $\cos 3-44$ & This study \\
\hline EHW380 & $\operatorname{cox} 2(1-25,89-91):: A R G 8^{m}$ & This study \\
\hline EHW383 & $\operatorname{cox} 2(1-6,15-25,89-91):: A R G 8^{m}$ & This study \\
\hline EHW384 & $\operatorname{cox} 2\left(1,2-6^{*}, 15-25,89-91\right):: A R G 8^{m d}$ & This study \\
\hline EHW $391^{f}$ & $\cos 3-45$ & This study \\
\hline EHW392 ${ }^{f}$ & $\cos 3-46$ & This study \\
\hline EHW393 ${ }^{f}$ & $\cos 3-47$ & This study \\
\hline EHW409 & $\operatorname{cox} 2(1-14,46-75,89-91):: A R G 8^{m}$ & This study \\
\hline EHW410 & $\operatorname{cox} 2(1-6,46-75,89-91):: A R G 8^{m}$ & This study \\
\hline EHW411 & $\operatorname{cox} 2\left(1,2-6^{*}, 46-75,89-91\right):: A R G 8^{m d}$ & This study \\
\hline EHW412 & $\operatorname{cox} 2(1-14,22-45,89-91):: A R G 8^{m}$ & This study \\
\hline
\end{tabular}


TABLE 1. Continued

\begin{tabular}{lll}
\hline Strain name & \multicolumn{1}{c}{ COX2 or COX3 allele } & Source or reference \\
\hline EHW413 & $\operatorname{cox} 2(1-6,22-45,89-91):: A R G 8^{\mathrm{m}}$ & This study \\
EHW414 & $\operatorname{cox} 2\left(1,2-6^{*}, 22-45,89-91\right):: A R G 8^{\text {md }}$ & This study \\
$\begin{array}{l}\text { Mixed lineage strain } \\
\text { TF236 }\end{array}$ & $\operatorname{cox} 3:: \arg 8^{m}-1$ & Bonnefoy and Fox (2000)
\end{tabular}

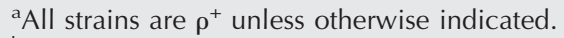

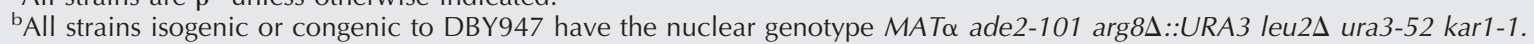

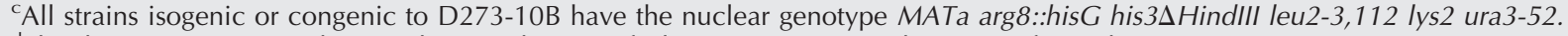

dThe designation " $2-6$ " denotes the introduction of silent mutations into the mRNA for codons 2-6.

eThe genotype for NSG171 $\rho^{\circ}$ is MAT $\alpha$ ade2 arg8::hisG lys2 ura3s.

${ }^{\text {f}}$ These strains contain a $\rho^{+}$genome with the indicated allele at the COX3 locus and the cox2-62 allele at the COX2 locus.

'The genotype for TF236 is MATa arg8::hisG his3? lys2 ura3-52 inols::HIS3 pet9 [cox3::arg8 $\left.{ }^{m}-1 \rho^{+}\right]$.

the pre-Cox2p leader peptide (Bonnefoy et al. 2001), and we hypothesize that interplay among these signals in vivo may ensure proper timing of pre-Cox $2 p$ synthesis and assembly into cytochrome $c$ oxidase.

\section{MATERIALS AND METHODS}

\section{Strains, media, and genetic methods}

S. cerevisiae strains utilized in this study are shown in Table 1. All phenotypic and genetic analyses were performed in strains isogenic or congenic to strain D273-10B (ATCC \#25627). Standard genetic methods were utilized (Sherman et al. 1974; Fox et al. 1991; Guthrie and Fink 1991). Yeast were grown in complete medium ( $1 \%$ yeast extract, $2 \%$ bacto-peptone, $50 \mathrm{mg}$ adenine/L) or synthetic complete medium ( $0.67 \%$ yeast nitrogen base supplemented with appropriate amino acids) with $2 \%$ glucose, $2 \%$ raffinose, $2 \%$ galactose, or $3 \%$ ethanol $/ 3 \%$ glycerol as indicated.

\section{Mutagenesis of $\operatorname{cox} 2:: A R G 8^{m}$}

Most cox2::ARG8 $8^{m}$ derivative alleles were PCR amplified from plasmid pNB95 (Bonnefoy et al. 2001) using synthetic oligonucleotides and $P f u$ (Stratagene), $P f u$ Turbo (Stratagene), or Taq DNA polymerase (GIBCO BRL) and either standard PCR or fusion PCR (Ho et al. 1989) techniques. These PCR products then were subcloned into the PacI-EagI restriction sites of plasmid pNB81 (Bonnefoy and Fox 2000). Alleles reintroducing portions of the COX2 leader peptide at the COX2 locus were PCR amplified from the following plasmids: pJM2 for codons 2-14 (Mulero and Fox 1993); pNB134 for codons 2-6 (N. Bonnefoy, unpubl.); and pNB148 for recoded codons 2-6 (N. Bonnefoy, unpubl.). PCR products were subcloned into the PacI-NsiI sites of plasmid pEHW112 (cox2[1,15-25,89-91]::ARG8 ${ }^{m}$; E.H. Williams, unpubl.). Alleles reintroducing portions of the leader peptide at the COX3 locus were amplified from these pEHW112 derivative plasmids and subcloned into the PacI-NsiI sites of pEHW160 (cox2[1,15-25,89-91]::ARG $8^{m}$ at COX3; unpubl.). All alleles were confirmed by sequencing with a primer located $\sim 155$ nt downstream of the cox2::ARG8 $8^{m}$ fusion junction.

\section{Mitochondrial transformation and strain construction}

Plasmids were transformed into DFS160 $\rho^{\circ}$ (Steele et al. 1996) by high-velocity microprojectile bombardment (Bonnefoy and Fox
2001). Synthetic $\rho^{-}$strains were identified by their ability to rescue arginine prototrophy when mated to an $\arg 8^{m}-1$ mutant, TF236 (Bonnefoy and Fox 2000). Synthetic $\rho^{-}$mtDNA was cytoduced into NB40-3C (cox2-62; Bonnefoy and Fox 2000) to create haploid, $\rho^{+}$recombinant cytoductants. Recombinants were identified by rescue of respiratory growth when mated to NB63 (cox2-107) for alleles at the COX2 locus or by rescue of arginine prototrophy when mated to NB71 $\left(\operatorname{cox} 3:: \arg 8^{m}-1\right)$ for alleles at the COX3 locus (Bonnefoy and Fox 2000). To confirm the $\rho^{+}$recombinant alleles by sequencing, alleles at COX2 were PCR amplified with a primer located $\sim 315 \mathrm{nt}$ upstream of the COX2 AUG and a primer in $A R G 8^{m}$, whereas alleles at $C O X 3$ were amplified with a primer located $\sim 665 \mathrm{nt}$ upstream of the COX3 AUG and the same $A R G 8^{m}$ primer.

\section{Selection and characterization of spontaneous $\mathrm{Arg}^{+}$mutants}

Independent 2-mL cultures in complete glucose medium were grown overnight to late log phase or saturation. One hundred to $200 \mu \mathrm{L}$ were pelleted, resuspended in minimal medium, and spread on synthetic complete medium lacking arginine. Mitochondrially encoded mutations were identified genetically in three ways: (1) arginine auxotrophy was observed for $\rho^{\circ}$ derivatives due to dependence of $\mathrm{Arg}^{+}$growth on the presence of mtDNA, (2) arginine prototrophy was observed in a diploid formed by mating the mutant with a wild-type $\rho^{\circ}$ (NSG171 $\rho^{\circ}$, Table 1 ), and (3) arginine auxotrophy was observed in a diploid formed by mating $\rho^{\circ}$ derivatives of each mutant with a wild-type strain $\rho^{+}$for the same mitochondrial DNA. The genetic lesion responsible was identified by PCR amplification and sequencing of the $\operatorname{cox} 2:: A R G 8^{m}$ region as described above.

\section{Selection and characterization of high copy suppressors}

Approximately 10,400 $\mathrm{Leu}^{+}$transformants of EHW155 $\left(\operatorname{cox} 2[1,15-25,89-91]:: A R G 8^{m}\right)$ with a $2 \mu$ genomic library in Yep13 (Nasmyth and Tatchell 1980) were assayed for growth on medium lacking arginine. Four plasmids produced $\mathrm{Arg}^{+}$growth after isolation from yeast and retransformation into the host strain. Inserts were partially sequenced using primers specific to Yep13. ORFs on three of these plasmids were subcloned either by restriction diges- 
tion of the parental plasmids or by PCR amplification of candidate ORFs.

TIF3 (eIF4B) was targeted to the mitochondrial matrix by fusion to the first 25 residues of Cox4p (Pinkham et al. 1994). Briefly, oligonucleotides encoding the targeting sequence were used in fusion PCR (Ho et al. 1989) with oligonucleotides containing endogenous Bam HI and HindIII restriction sites located upstream of and downstream from TIF3. PCR-amplified alleles of TIF3 were used to create three plasmids: pEHW177 expresses untargeted TIF3 from pRS315 (Sikorski and Hieter 1989), pEHW178 expresses cox4::TIF3 from pRS315, and pEHW189 expresses cox4::TIF3 from YEp351 (Hill et al. 1986). All constructs utilize the endogenous TIF3 promoter. The cox4::TIF3 fusion junction was sequenced using a primer $\sim 140 \mathrm{nt}$ upstream of the TIF3 start codon.

Two alleles of PET111 (PET111 and PET111-20) also were tested for suppression. EHW155 (cox2[1,15-25,89-91]::ARG8 $\left.{ }^{m}\right)$ was transformed with plasmids Yep352 (empty vector; Hill et al. 1986), pJM20 (PET111 in Yep352; Mulero and Fox 1993), and pJM57 (PET111-20 in Yep352; Mulero and Fox 1993) and tested for growth on media containing and lacking arginine.

\section{Northern and Western analyses}

Total RNA was prepared and Northern blot analyses were performed as described (Costanzo et al. 2000) except that RNA was supplemented with ethidium bromide prior to electrophoresis and was blotted to Hybond XL membrane (Amersham Pharmacia Biotech). $\operatorname{cox} 2:: A R G 8^{m}$ mRNA was detected using a DNA probe to the $A R G 8^{m}$ coding region, and loading was standardized by hybridization to a $15 S$ ribosomal RNA probe (Shen and Fox 1989).

Total cellular protein was prepared as described (Yaffe 1991) from cells grown in complete medium with $2 \%$ raffinose or galactose. Seventy-five micrograms of protein per sample were separated on 12\% acrylamide gels and probed with a 1:5000 dilution of anti-Arg8p polyclonal antibody (Steele et al. 1996). Secondary goat anti-rabbit IgG antibodies conjugated to HRP (1:10,000 dilution; GIBCO BRL) were detected by chemiluminescence using the ECL detection kit (Amersham Pharmacia Biotech).

\section{ACKNOWLEDGMENTS}

E.H. Williams is a Howard Hughes Medical Institute Predoctoral Fellow. This work was supported by the National Institutes of Health (Grant GM29362 to T.D.F.).

The publication costs of this article were defrayed in part by payment of page charges. This article must therefore be hereby marked "advertisement" in accordance with 18 USC section 1734 solely to indicate this fact.

Received November 20, 2002; accepted December 16, 2002.

\section{REFERENCES}

Altmann, M., Wittmer, B., Methot, N., Sonenberg, N., and Trachsel, H. 1995. The Saccharomyces cerevisiae translation initiation factor Tif3 and its mammalian homologue, eIF-4B, have RNA annealing activity. EMBO J. 14: 3820-3827.

Anderson, S., De Bruijn, M.H.L., Coulson, A.R., Eperon, I.C., Sanger,
F., and Young, I.G. 1982. Complete sequence of bovine mitochondrial DNA: Conserved features of the mammalian mitochondrial genome. J. Mol. Biol. 156: 683-717.

Baim, S.B., Pietras, D.F., Eustice, D.E., and Sherman, F. 1985. A mutation allowing an mRNA secondary structure diminishes translation of Saccharomyces cerevisiae iso-1-cytochrome c. Mol. Cell. Biol. 5: 1839-1846.

Bi, X., Ren, J., and Goss, D.J. 2000. Wheat germ translation initiation factor eIF4B affects eIF4A and eIFiso4F helicase activity by increasing the ATP binding affinity of eIF4A. Biochemistry 39: 5758-5765.

Bonnefoy, N. and Fox, T.D. 2000. In vivo analysis of mutated initiation codons in the mitochondrial COX2 gene of Saccharomyces cerevisiae fused to the reporter gene $A R G 8^{m}$ reveals lack of downstream reinitiation. Mol. Gen. Genet. 262: 1036-1046.

- 2001. Genetic transformation of Saccharomyces cerevisiae mitochondria. Meth. Cell. Biol. 65: 381-396.

Bonnefoy, N., Bsat, N., and Fox, T.D. 2001. Mitochondrial translation of Saccharomyces cerevisiae COX2 mRNA is controlled by the nucleotide sequence specifying the pre-Cox $2 \mathrm{p}$ leader peptide. Mol. Cell. Biol. 21: 2359-2372.

Bui, D.M., Gregan, J., Jarosch, E., Ragnini, A., and Schweyen, R.J. 1999. The bacterial magnesium transporter CorA can functionally substitute for its putative homologue Mrs2p in the yeast inner mitochondrial membrane. J. Biol. Chem. 274: 20438-20443.

Costanzo, M.C., Bonnefoy, N., Williams, E.H., Clark-Walker, G.D., Fox, T.D. 2000. Highly diverged homologs of Saccharomyces cerevisiae mitochondrial mRNA-specific translational activators have orthologous functions in other budding yeasts. Genetics 154: 9991012.

Dunstan, H.M., Green-Willms, N.S., and Fox TD. 1997. In vivo analysis of Saccharomyces cerevisiae COX2 mRNA 5' -untranslated leader functions in mitochondrial translation initiation and translational activation. Genetics 147: 87-100.

Folley, L.S. and Fox, T.D. 1994. Reduced dosage of genes encoding ribosomal protein S18 suppresses a mitochondrial initiation codon mutation in Saccharomyces cerevisiae. Genetics 137: 369-379.

Fox, T.D. 1996a. Genetics of mitochondrial translation. In Translational control (eds. J.W.B. Hershey et al.), pp. 733-758. Cold Spring Harbor Press, Cold Spring Harbor, NY.

- 1996b. Translational control of endogenous and recoded nuclear genes in yeast mitochondria: Regulation and membrane targeting. Experientia 52: 1130-1135.

Fox, T.D., Folley, L.S., Mulero, J.J., McMullin, T.W., Thorsness, P.E., Hedin, L.O., and Costanzo, M.C. 1991. Analysis and manipulation of yeast mitochondrial genes. Methods Enzymol. 194: 149-165.

Geier, B.M., Schagger, H., Ortwein, C., Link, T.A., Hagen, W.R., Brandt, U., and Von Jagow, G. 1995. Kinetic properties and ligand binding of the eleven-subunit cytochrome-c oxidase from Saccharomyces cerevisiae isolated with a novel large-scale purification method. Eur. J. Biochem. 227: 296-302.

Green-Willms, N.S., Fox, T.D., and Costanzo, M.C. 1998. Functional interactions between yeast mitochondrial ribosomes and mRNA 5'-untranslated leaders. Mol. Cell. Biol. 18: 1826-1834.

Green-Willms, N.S., Butler, C.A., Dunstan, H.M., and Fox, T.D. 2001. Pet111p, an inner membrane-bound translational activator that limits expression of the Saccharomyces cerevisiae mitochondrial gene COX2. J. Biol. Chem. 276: 6392-6397.

Gregan, J., Bui, D.M., Pillich, R., Fink, M., Zsurka, G., and Schweyen, R.J. 2001. The mitochondrial inner membrane protein Lpe10p, a homologue of Mrs2p, is essential for magnesium homeostasis and group II intron splicing in yeast. Mol. Gen. Genet. 264: 773-781.

Guthrie, C. and Fink, G.R. 1991. Guide to yeast genetics and molecular biology. In Methods in enzymology, vol. 194 (eds J.N. Abelson and M.I. Simon), Academic Press, San Diego, CA.

Hardy, C.M. and Clark-Walker, G.D. 1990. Nucleotide sequence of the cytochrome oxidase subunit 2 and Val-tRNA genes and surrounding sequences from Kluyveromyces lactis $\mathrm{K} 8$ mitochondrial DNA. Yeast 6: 403-410.

He, S. and Fox, T.D. 1997. Membrane translocation of mitochondri- 
ally coded Cox $2 p$ : Distinct requirements for export of amino- and carboxy-termini, and dependence on the conserved protein Oxalp. Mol. Biol. Cell 8: 1449-1460.

Hill, J.E., Myers, A.M., Koerner, T.J., and Tzagoloff, A. 1986. Yeast/E. coli shuttle vectors with multiple unique restriction sites. Yeast 2: 163-167.

Ho, S.N., Hunt, H.D., Horton, R.M., Pullen, J.K., and Pease, L.R. 1989. Site-directed mutagenesis by overlap extension using the polymerase chain reaction. Gene 77: 51-59.

Hoeben, P., Weiller, G., and Clark-Walker, G.D. 1993. Larger rearranged mitochondrial genomes in Dekkera/Brettanomyces yeasts are more closely related than smaller genomes with a conserved gene order. J. Mol. Evol. 36: 263-269.

Jauniaux, J.-C., Urrestarazu, L.A., and Wiame, J.-M. 1978. Arginine metabolism in Saccharomyces cerevisiae: Subcellular localization of the enzymes. J. Bacteriol. 133: 1096-1107.

Kontos, H., Napthine, S., and Brierley, I. 2001. Ribosomal pausing at a frameshifter RNA pseudoknot is sensitive to reading phase but shows little correlation with frameshift efficiency. Mol. Cell. Biol. 21: 8657-8670.

Linder, P.L. and Slonimski, P.P. 1989. An essential yeast protein, encoded by duplicated genes TIF1 and TIF2 and homologous to the mammalian translation initiation factor eIF-4A, can suppress a mitochondrial missense mutation. Proc. Natl. Acad. Sci. 86: 22862290.

Lu, G. and Hanson, M.R. 1994. A single homogeneous form of ATP6 protein accumulates in petunia mitochondria despite the presence of differentially edited atp6 transcripts. Plant Cell 6: 1955-1968.

McNicholas, P., Salavati, R., and Oliver, D. 1997. Dual regulation of Escherichia coli secA translation by distinct upstream elements. J. Mol. Biol. 265: 128-141.

Misra, V.K. and Draper, D.E. 1998. On the role of magnesium ions in RNA stability. Biopolymers 48: 113-135.

Mulero, J.J. and Fox, T.D. 1993. Alteration of the Saccharomyces cerevisiae COX2 5'-untranslated leader by mitochondrial gene replacement and functional interaction with the translational activator protein PET111. Mol. Biol. Cell 4: 1327-1335.

Müller, P.P., Reif, M.K., Zonghou, S., Sengstag, C., Mason, T.L., and Fox, T.D. 1984. A nuclear mutation that post-transcriptionally blocks accumulation of a yeast mitochondrial gene product can be suppressed by a mitochondrial gene rearrangement. J. Mol. Biol. 175: 431-452.

Naithani, S., Saracco, S.A., Butler, C.A., and Fox, T.D. 2003. Interactions among COX1, COX2 and COX3 mRNA-specific translational activator proteins on the inner surface of the mitochondrial inner membrane of Saccharomyces cerevisiae. Mol. Biol. Cell 14: 324-333.

Nakatogawa, H. and Ito, K. 2001. Secretion monitor, SecM, undergoes self-translation arrest in the cytosol. Mol. Cell 7: 185-192.

Nasmyth, K.A. and Tatchell, K. 1980. The structure of transposable yeast mating type loci. Cell 19: 753-764.

Oliver, D., Norman, J., and Sarker, S. 1998. Regulation of Escherichia coli secA by cellular protein secretion proficiency requires an intact gene $\mathrm{X}$ signal sequence and an active translocon. J. Bacteriol. 180: $5240-5242$.

Papadopoulou, B., Dekker, P., Blom, J., and Grivell, L.A. 1990. A 40 kd protein binds specifically to the $5^{\prime}$-untranslated regions of yeast mitochondrial mRNAs. EMBO J. 9: 4135-4143.

Picking, W.D., Picking, W.L., Odom, O.W., and Hardesty, B. 1992. Fluorescence characterization of the environment encountered by nascent polyalanine and polyserine as they exit Escherichia coli ribosomes during translation. Biochemistry 31: 2368-2375.
Pinkham, J.L., Dudley, A.M., and Mason, T.L. 1994. T7 RNA polymerase-dependent expression of COXII in yeast mitochondria. Mol. Cell. Biol. 14: 4643-4652.

Pratje, E., Mannhaupt, G., Michaelis, G., and Beyreuther, K. 1983. A nuclear mutation prevents processing of a mitochondrially encoded membrane protein in Saccharomyces cerevisiae. EMBO J. 2: $1049-1054$.

Rogers Jr., G.W., Richter, N.J., Lima, W.F., and Merrick, W.C. 2001. Modulation of the helicase activity of eIF4A by eIF4B, eIF4H, and eIF4F. J. Biol. Chem. 276: 30914-30922.

Sachs, M.S. and Geballe, A.P. 2002. Biochemistry. Sense and sensitivity-controlling the ribosome. Science 297: 1820-1821.

Sanchirico, M.E., Fox, T.D., and Mason, T.L. 1998. Accumulation of mitochondrially synthesized Saccharomyces cerevisiae Cox $2 \mathrm{p}$ and Cox $3 p$ depends on targeting information in untranslated portions of their mRNAs. EMBO J. 17: 5796-5804.

Schmidt, U., Maue, I., Lehmann, K., Belcher, S.M., Stahl, U., and Perlman, P.S. 1998. Mutant alleles of the MRS2 gene of yeast nuclear DNA suppress mutations in the catalytic core of a mitochondrial group II intron. J. Mol. Biol. 282: 525-541.

Sevarino, K.A. and Poyton, R.O. 1980. Mitochondrial biogenesis: Identification of a precursor to yeast cytochrome $c$ oxidase subunit II, an integral polypeptide. Proc. Natl. Acad. Sci. 77: 142-146.

Shen, Z. and Fox, T.D. 1989. Substitution of an invariant nucleotide at the base of the highly conserved "530-loop" of 15S rRNA causes suppression of mitochondrial ochre mutations. Nucleic Acids Res. 17: 4535-4539.

Sherman, F., Fink, G.R., and Lawrence, C.W. 1974. Methods in Yeast Genetics. Cold Spring Harbor Laboratory, Cold Spring Harbor, NY.

Sikorski, R.S. and Hieter, P. 1989. A system of shuttle vectors and yeast host strains designed for efficient manipulation of DNA in Saccharomyces cerevisiae. Genetics 122: 19-27.

Steele, D.F., Butler, C.A., and Fox, T.D. 1996. Expression of a recoded nuclear gene inserted into yeast mitochondrial DNA is limited by mRNA-specific translational activation. Proc. Natl. Acad. Sci. 93: 5253-5257.

Steffens, G.J. and Buse, G. 1979. Studies on cytochrome $c$ oxidase (IV): Primary structure and function of subunit II. Hoppe-Seyler's Z. Physiol. Chem. 360: 613-619.

Tenson, T. and Ehrenberg, M. 2002. Regulatory nascent peptides in the ribosomal tunnel. Cell 108: 591-594.

Thanaraj, T.A. and Argos, P. 1996. Ribosome-mediated translational pause and protein domain organization. Protein Sci. 5: 1594-1612.

Torello, A.T., Overholzer, M.H., Cameron, V.L., Bonnefoy, N., and Fox, T.D. 1997. Deletion of the leader peptide of the mitochondrially encoded precursor of Saccharomyces cerevisiae cytochrome $c$ oxidase subunit II. Genetics 145: 903-910.

Waldherr, M., Ragnini, A., Jank, B., Teply, R., Wiesenberger, G., and Schweyen, R.J. 1993. A multitude of suppressors of group II intron-splicing defects in yeast. Curr. Genet. 24: 301-306.

Wiesenberger, G., Waldherr, M., and Schweyen, R.J. 1992. The nuclear gene MRS2 is essential for the excision of group II introns from yeast mitochondrial transcripts in vivo. J. Biol. Chem. 267: 69636969.

Yaffe, M.P. 1991. Analysis of mitochondrial function and assembly. Methods Enzymol. 194: 627-643.

Yusupova, G.Z., Yusupov, M.M., Cate, J.H., and Noller, H.F. 2001. The path of messenger RNA through the ribosome. Cell 106: 233 241. 

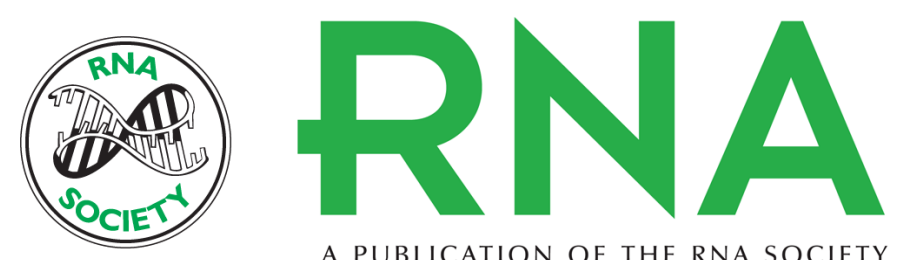

A PUBLICATION OF THE RNA SOCIETY

\section{Antagonistic signals within the COX2 mRNA coding sequence control its translation in Saccharomyces cerevisiae mitochondria}

ELIZABETH H. WILLIAMS and THOMAS D. FOX

RNA 2003 9: 419-431

References This article cites 54 articles, 24 of which can be accessed free at: http://rnajournal.cshlp.org/content/9/4/419.full.html\#ref-list-1

License

Email Alerting Receive free email alerts when new articles cite this article - sign up in the box at the Service top right corner of the article or click here. 